\title{
The role of corticotrophin-releasing hormone in the diagnosis of Cushing's syndrome
}

\author{
C J Peters, H L Storr, A B Grossman and M O Savage \\ Department of Endocrinology, Barts and The London School of Medicine and Dentistry, Queen Mary University of London, London EC1M 6BQH, UK \\ (Correspondence should be addressed to M O Savage who is now at Department of Endocrinology, William Harvey Research Institute, John Vane Science \\ Centre, Charterhouse Square, London EC1M 6BQ, UK; Email: m.o.savage@qmul.ac.uk)
}

\begin{abstract}
Background: Corticotrophin-releasing hormone (CRH) was identified by Vale and co-workers in 1981 and has since been used extensively in the diagnosis of ACTH-dependent Cushing's syndrome (CS). It was hoped that the CRH test would discriminate between pituitary and ectopic ACTH secretion. In adults, a rise from basal to peak plasma cortisol of $\geq 20 \%$ and ACTH of $\geq 50 \%$ is consistent with Cushing's disease (CD). Methods: Twenty-seven paediatric patients, with CD (mean age \pm s.D. 13.1 \pm 3.2 ; range 6.4-17.8 years) were investigated in our centre between 1982 and 2005.

Results: During the CRH test, all patients showed an increase in cortisol of $>20 \%$ (range 106-554\%). In one patient with ectopic ACTH syndrome, there was no increase in cortisol after CRH. In six paediatric patients with CS due to primary adrenal hyperplasia, no patient showed an increase in cortisol after CRH of $>1 \%$.

Conclusions: A further suggested use of $\mathrm{CRH}$ is to increase the sensitivity of the central to peripheral and interpetrosal ratios of ACTH during inferior petrosal sinus catheterisation (IPSS). Bilateral IPSS with human CRH (hCRH) has been performed in our unit in 21 children with $\mathrm{CD}$, as part of the preoperative preparation prior to trans-sphenoidal surgery (TSS). Its principal role was to identify the site of the microadenoma. Sixteen of 21 patients (76\%) who underwent IPSS with hCRH were cured following TSS. In our view, the CRH test is of value during IPSS by clarifying the position of the microadenoma and in this way contributed to the overall outcome of TSS in paediatric patients with CD.
\end{abstract}

European Journal of Endocrinology 155 S93-S98

\section{Introduction}

Cushing's syndrome (CS) is a clinical syndrome caused by excess circulating glucocorticoid concentrations resulting from either endogenous secretion or exogenous administration. CS in childhood and adolescence is rare and there are some specific differences in presentation in paediatric patients compared with adults. In the adult population, CS of any aetiology is more common in women. In childhood, adrenocortical tumours and primary adrenal hyperplasia also occur predominantly in females (1). However, in young patients with $\mathrm{CD}$, unlike adults, there is a male predominance (2).

The age range at presentation of CS, from neonatal CS to adolescent CS, tends to reflect the different underlying aetiologies (Fig. 1). Pituitary imaging and petrosal sinus catheter data in Cushing's disease (CD) and response to pituitary radiotherapy also differ from adult data.

This paper was presented at the 4th Ferring Pharmaceuticals International Paediatric Endocrinology Symposium, Paris (2006). Ferring Pharmaceuticals has supported the publication of these proceedings.
Childhood CS typically presents with a history of weight gain and growth failure, virilisation and emotional lability. A family history of CS, skin lentigines or freckles and other endocrine disease can be indicative of primary pigmented adrenocortical disease (PPNAD) associated with Carney complex. Lethargy or depression, headaches, easy bruising and acne are less specific. Some paediatric patients have many of the classical features of CS, whereas others have relatively few signs, e.g. obesity with no other features. Therefore, in our experience, the key findings on examination are a reduction in height SDS associated with an increased BMI SDS, a typical facial appearance, purple striae, virilisation and, occasionally, hypertension.

\section{Confirmation of diagnosis of Cushing's syndrome}

CS is characterised biochemically by impairment of the normal feedback control of the hypothalamo-pituitaryadrenal axis with loss of the normal circadian rhythm of cortisol secretion. The diagnosis of CS is based on the 


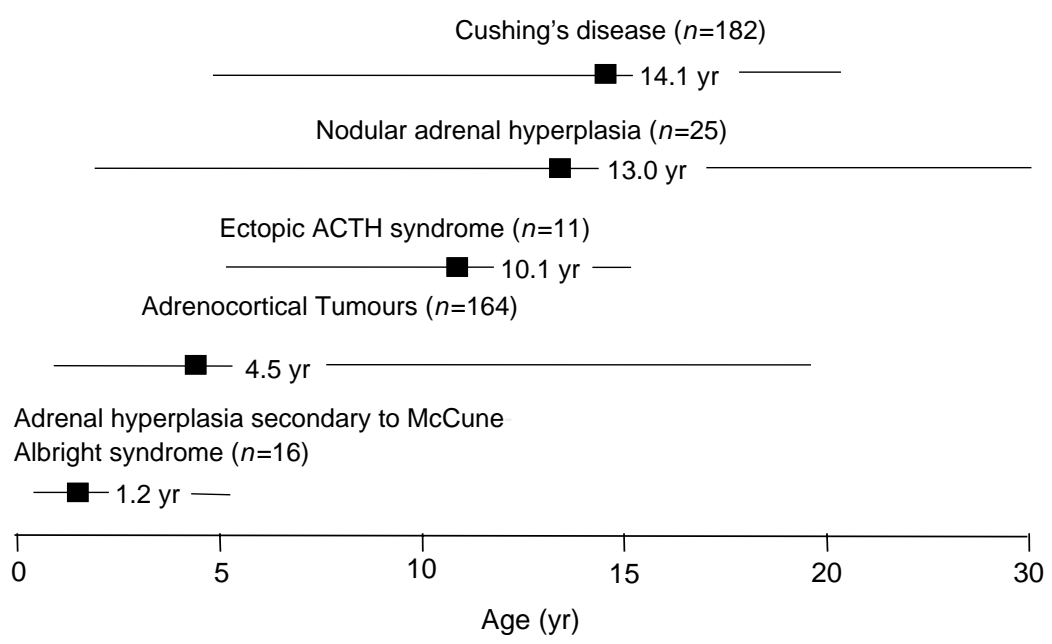

Figure 1 Differing aetiologies of paediatric CS from the literature ( $n=398$ cases) shown at ages of peak incidence.

demonstration of abnormalities of the pituitary-adrenal axis and its investigation consists of two basic stages; first, the demonstration of CS and secondly, the identification of the precise aetiology.

\section{Demonstration of CS}

Three consecutive 24-h collections for urinary free cortisol (UFC) can be a helpful screening test. Overall, UFC measurements have a high sensitivity, but relatively low specificity; therefore, if several UFC collections are normal, CS is unlikely (3).

Elevated sleeping midnight cortisol appears to be the best discriminator of CS. This is in contrast with the other time points where values are often within, or only slightly above, the normal range (4). In our series, all patients with CS of various different aetiologies had a detectable value $(>50 \mathrm{nmol} / \mathrm{l})$ and therefore, a single undetectable sleeping midnight serum cortisol less than this value effectively excludes CS.

The low-dose dexamethasone suppression test (LDDST) is also useful. Oral dexamethasone $0.5 \mathrm{mg}$ (or $30 \mu \mathrm{g} / \mathrm{kg}$ per day in young children) is given every $6 \mathrm{~h}$ over $48 \mathrm{~h}$ with the measurement of $0900 \mathrm{~h}$ serum cortisol at 0 and $48 \mathrm{~h}$. An overnight test after $1 \mathrm{mg}$ dexamethasone at night followed by a 0900-h cortisol measurement is also helpful. The cortisol level in normal individuals during the LDDST should be suppressed to $<$ $50 \mathrm{nmol} / \mathrm{l}$. The same cut-off cortisol level of $<50 \mathrm{nmol} / \mathrm{l}$ also applies in the overnight dexamethasone suppression test. In our experience, a small proportion of patients (2/30) with CD (pituitary corticotroph adenomas) suppress normally during LDDST, but patients with CS due to other aetiologies do not.

\section{Defining the aetiology}

CS can be divided into adrenocorticotrophic hormone (ACTH)-independent and -dependent aetiologies (Fig. 2).
In ACTH-independent CS, the primary abnormality lies within the adrenal gland (adrenocortical tumour and primary adrenal hyperplasia) or it is due to exogenous glucocorticoid administration. ACTH is suppressed by negative feedback and is undetectable. In ACTH-dependent CS, caused by either CD (ACTH-secreting pituitary corticotroph adenoma) or ectopic ACTH syndrome, the stimulus for cortisol secretion comes from ACTH, which is detectable in the serum. Measurement of plasma ACTH is, therefore, very helpful, and we take a value of $>$ $20 \mathrm{ng} / \mathrm{l}$ as evidence in favour of ACTH-dependence, while a level $<10 \mathrm{ng} / \mathrm{l}$ indicates ACTH-independence. With levels between 10 and $20 \mathrm{ng} / \mathrm{l}$, the ACTH response to the corticotrophin-releasing hormone (CRH) test (see below) becomes very helpful. The high dose dexamethasone suppression test $(2 \mathrm{mg}, 6$ hourly $\times 48 \mathrm{~h})$ shows suppression of cortisol by $>50 \%$ of the basal value in CD, but no significant suppression in the majority of patients with ectopic ACTH syndrome.

Pituitary imaging by high resolution computed tomography or magnetic resonance imaging (MRI) may contribute to localisation of pituitary adenomas, but most corticotroph microadenomas are $<4 \mathrm{~mm}$ (5) and isodense with the pituitary tissue. We were able to demonstrate microadenoma on imaging in only 6 out of 17 patients and concordance between pituitary imaging and surgical findings only in nine patients (6). Adrenal imaging is useful, particularly, in case of ACTH-independent CS. In our series of children with CS, all patients with PPNAD or adrenal tumour showed suppression of ACTH and diagnosis was confirmed by adrenal MRI.

\section{The use of the CRH test in clinical practice}

CRH was first described in 1981 by Vale and colleagues as an ovine peptide that stimulated 


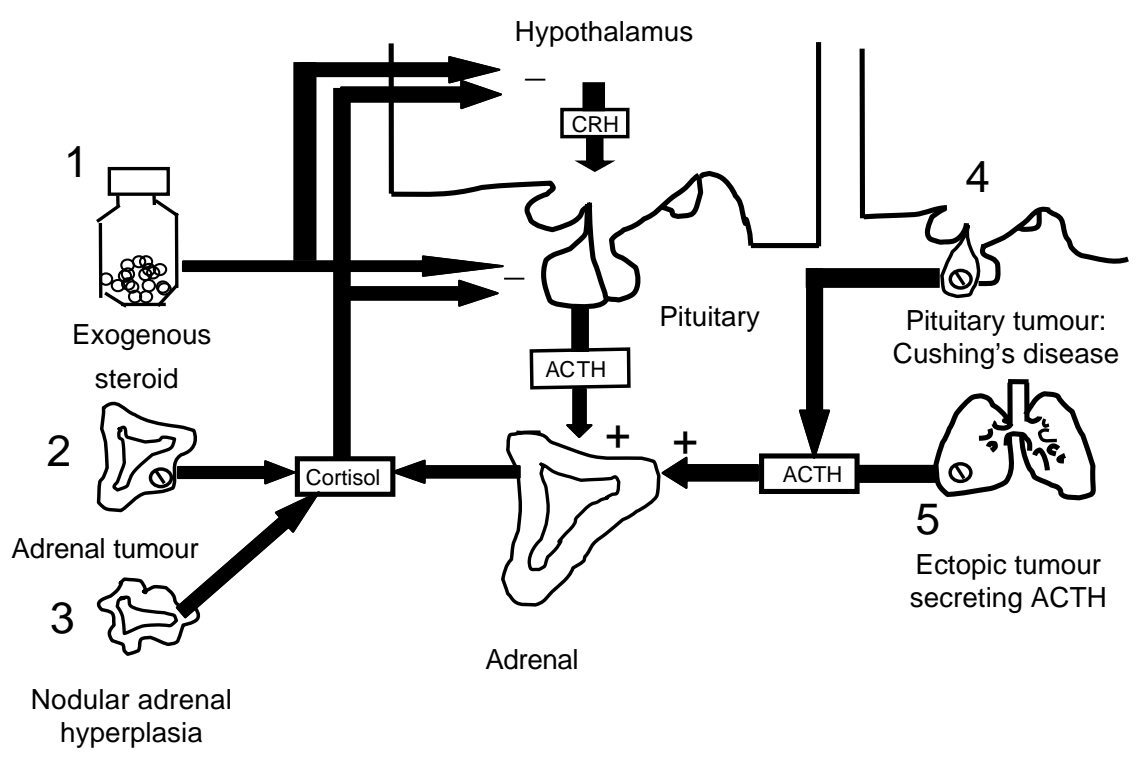

Figure 2 Differential diagnosis of paediatric CS.

secretion of corticotrophin and $\beta$-endorphin (7). The human $\mathrm{CRH}(\mathrm{hCRH})$ gene was cloned and sequenced 2 years later (8). It is a 41 -amino acid peptide derived by enzymatic cleavage from a 191-amino acid preprohormone and primarily released by the paraventricular nucleus of the hypothalamus.

The use of $\mathrm{CRH}$ as an investigative tool in CS was subsequently established $(9,10)$. It was observed that the majority of adult patients with $\mathrm{CD}$ showed an excessive rise in serum cortisol in response to CRH stimulation, while those with ectopic ACTH syndrome (very rare in the paediatric setting) or adrenal adenomas failed to show a rise in cortisol. It is thought that the mechanism of action relates to an increase in CRH receptor expression in corticotroph adenomas compared with tumours ectopically secreting ACTH (3).

The $\mathrm{CRH}$ test has now become an established investigation to aid the discrimination between ACTHdependent and -independent CS. The rise in cortisol can be expressed as a percentage increase from the baseline value. The fasted child must have blood samples for cortisol and ACTH obtained at baseline and timed intervals up to $120 \mathrm{~min}$ from the time of administration of $1 \mu \mathrm{g} / \mathrm{kg}$ IV. Side effects of flushing, hypotension and a metallic taste in mouth have been reported, but are rarely severe.

\section{Response to CRH test}

In adults, a rise from basal to peak plasma cortisol of $\geq 20 \%$ and ACTH of $\geq 35-50 \%$ is suggested to be consistent with a diagnosis of $\mathrm{CD}(3,4,10)$. The timing of the calculated rise in ACTH and cortisol from basal levels can influence the interpretation of the response to CRH. It is thought that the most discriminating time for calculation of mean peak levels of ACTH is 15-30 min from mean basal values. For cortisol, this mean peak timing is 30-45 min from the baseline. Absolute values are not considered helpful, as the response to CRH appears to be qualitative rather than quantitative (3).

In a series of children and adolescents with $\mathrm{CD}$ reported by Magiakou et al. (11), 51 patients underwent the CRH test: $75 \%(30 / 40)$ of patients with pituitary adenomas had an increase in plasma ACTH $\geq 34 \%$ from baseline after CRH. There was no response to CRH in seven patients with non-pituitary CS. An increase in plasma cortisol $\geq 20 \%$ from baseline after CRH administration was demonstrated in $80 \%(35 / 44)$ of patients with $\mathrm{CD}$.

\section{Results from investigation of paediatric patients with CS at St Bartholomew's and the Royal London Hospitals}

We have used the CRH test in the investigation of 27 paediatric patients with $\mathrm{CD}$ in our centre between 1982 and 2005 (Fig. 3). The series included 16 males and 11 females (mean age \pm s.D. $13.1 \pm 3.2$ years; range $6.4-17.8$ years). During the CRH test $(1 \mu \mathrm{g} / \mathrm{kg}$ IV), all patients showed an increase in cortisol of $>20 \%$ (range 106-554\%). The mean change was $+97 \%$ (CI 60-134\%). In one patient with ectopic ACTH syndrome, there was no increase in cortisol after CRH. In six paediatric patients with CS due to primary adrenal hyperplasia, no patient showed an increase in cortisol after CRH of $>1 \%$.

Our results suggest a high sensitivity and specificity in this group of paediatric patients compared with adult studies that suggest a sensitivity of $86 \%$ and specificity of $95 \%$ for plasma ACTH responses, and a sensitivity of $91 \%$ and specificity of $95 \%$ for plasma cortisol responses (3). 

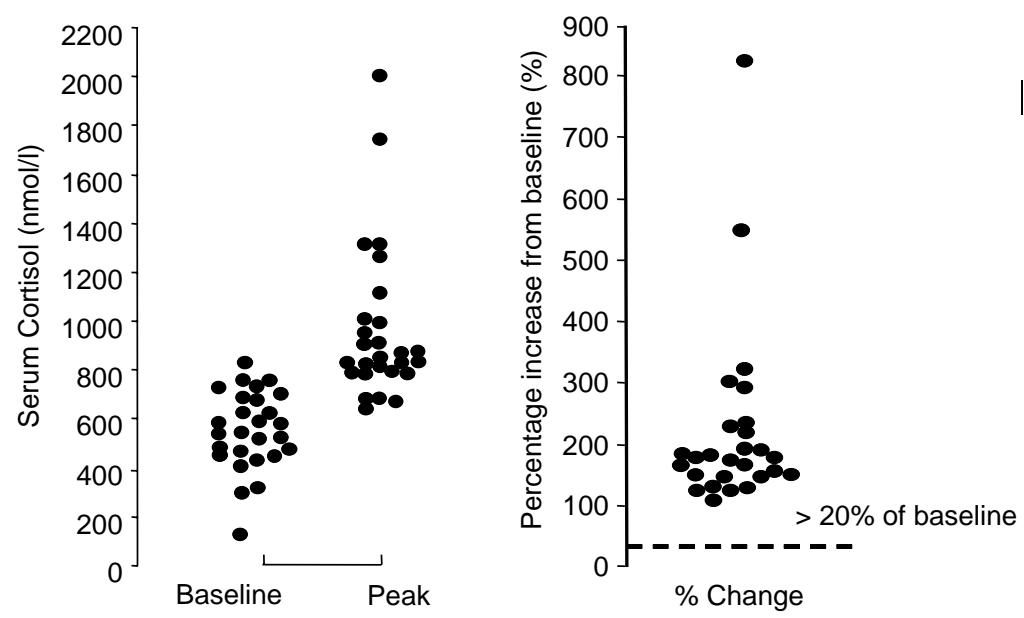

Figure 3 Serum cortisol responses to $\mathrm{CRH}(1 \mu \mathrm{g} / \mathrm{kg} \mathrm{IV})$ in paediatric CD $(n=27)$.

\section{Ovine versus human CRH}

Given the rarity of paediatric CS, most studies involving the use of the CRH test have been performed in adults, and have used ovine CRH rather than human peptide CRH. hCRH has been reported to produce quantitatively lower, but qualitatively similar responses to ovine CRH (3).

\section{Alternatives to the CRH test}

Vasopressin and desmopressin (a V2 and V3 vasopressin receptor agonist) stimulate ACTH release through the corticotroph vasopressin (V3) receptor and have been used as cheaper and more readily available alternatives to CRH. Desmopressin has been demonstrated to increase ACTH and cortisol secretion in $80-90 \%$ of adult patients with $\mathrm{CD}$, but may produce a response in up to $50 \%$ of ectopic ACTH-producing tumours (4). Newell-Price et al. found that published data on the desmopressin test suggest a sensitivity of $84 \%$ and specificity of $83 \%$ for cortisol responses and sensitivity of $77 \%$ and specificity of $73 \%$ for ACTH responses (3). This is inferior to the CRH test alone.

The use of vasopressin in combination with ovine CRH was demonstrated in adults with CS to show better quantitative responses in cortisol and ACTH increases from baseline than when CRH was used alone (3). However, the value of this combination has not been established. There are no published paediatric data for the use of vasopressin or desmopressin in this clinical setting.

\section{Inferior petrosal sinus sampling (IPSS)}

If $\mathrm{CD}$ is suspected, venous sampling from the inferior petrosal sinus (IPS) may help to confirm a central source of ACTH and lateralise the site of a potential pituitary tumour. This is of importance in guiding the site of potential subsequent trans-sphenoidal surgery (TSS). ACTH secretion may be intermittent and therefore CRH is used as a stimulating agent to increase the sensitivity of the test.

\section{Description of IPSS}

Two catheters are introduced radiologically into the left and right IPS. A third catheter is placed peripherally $(\mathrm{P})$ in the arm. Baseline samples are taken at approximately -5 and $0 \mathrm{~min}$ from each site. At $0 \mathrm{~min}, \mathrm{CRH}(100 \mu \mathrm{g}$ or $1 \mu \mathrm{g} / \mathrm{kg}$ in younger children) is injected as a bolus over 10 s peripherally. Simultaneous samples from the three sampling sites are taken at 0, 4 and 9 min from the start of administration of CRH.

ACTH is measured in all samples and is frozen within $10 \mathrm{~min}$ of the sampling. Cortisol is measured in all the peripheral samples. In IPSS, the principal difficulty arises from the positioning of the sampling catheter. Jugular venous samples do not consistently show lateralisation, but can be used if the petrosal sinus is difficult to access. No complications of IPSS in childhood have been described, but in adults (in whom experience is much more extensive) very rarely have neurological sequelae been reported.

\section{Response to CRH during IPSS}

The ratio of ACTH concentration in the right and left IPS to peripheral ACTH concentration (IPS:P ratio) is calculated (12). Newell-Price et al. reviewed published series of IPS data comparing results in CD and ectopic ACTH syndrome and found that applying the criteria of a basal IPS:P ratio of $\geq 2.0$ or a $\mathrm{CRH}$-stimulated ratio of $\geq 3.0$ reveals an overall sensitivity of $96 \%$ and specificity of $100 \%$ (3).

In addition, if the basal or stimulated ACTH level for one IPS sample is 1.4 times as high as the simultaneous contralateral side (the interpetrosal sinus gradient, IPSG), this suggests localisation of the pituitary tumour to the ipsilateral side (12). It has also 


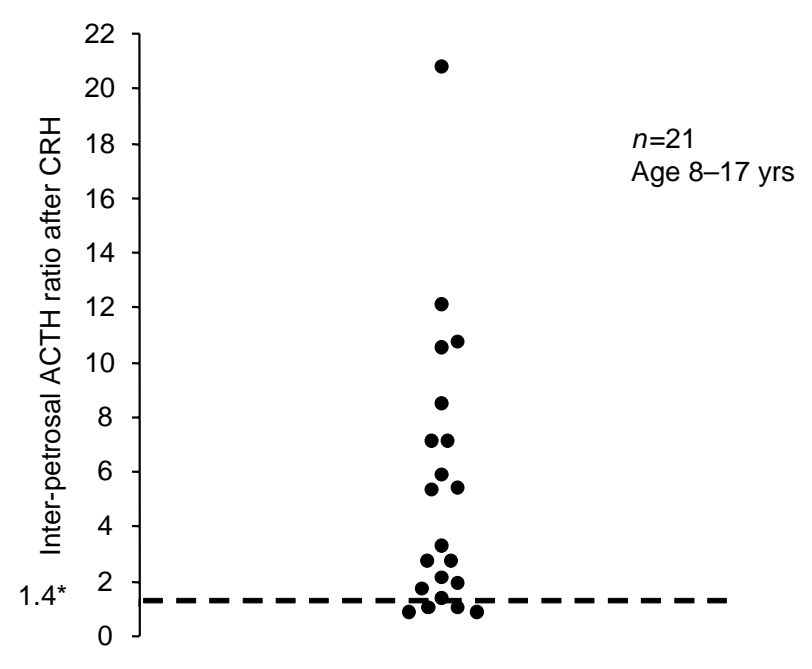

*ratio of $>1.4$ indicates lateralisation of ACTH secretion $17 / 21$ (81\%) showed lateralisation of ACTH secretion

Figure 4 Bilateral inferior petrosal sinus sampling for ACTH (1986-2005).

been reported that prolactin and growth hormone are often raised on the side of the tumour and that this is augmented by CRH.

Previous studies of the use of IPS in children suggest that correct prediction of lateralisation of a pituitary microadenoma after CRH occurs in $76-91 \%(11,13)$. However, a recent study on the use of IPS in children with CD described 94 children with an age range of 5.3-18.7 years. The authors found that IPS concurred with surgical location of microadenoma in $58 \%$ of cases (14). However, this figure rose to $70 \%(51 / 73)$ after exclusion of 18 centrally located lesions and four bilateral lesions.

\section{Results from investigation of patients with CS at St Bartholomew's and the Royal London Hospitals}

Bilateral IPSS with hCRH was introduced in our unit in 1986 and has been performed without sedation in 21 patients (age range 8.2-17.8 years) with CD (Fig. 4). Its principal role in children was to identify the site of the microadenoma and is used as part of the preoperative preparation prior to TSS.

Out of 21 children, 16 (76\%) demonstrated central ACTH secretion with a peak IPS:P ratio $\geq 3.0$ (mean 22.0; range 3.0-157.2). Also, in 16 (76\%) children, there was lateralisation of ACTH secretion with an IPSG $\geq 1.4$ (mean 5.7; range 1.4-20.8). In five children, the IPSG was $<1.4$ suggesting a mid-line lesion (15).

Sixteen patients were subsequently cured following TSS. In our view, the hCRH test is of value during IPSS by clarifying the position of the microadenoma and in this way contributes to the overall outcome of TSS in paediatric patients with $\mathrm{CD}$.

\section{Conclusions}

Paediatric CS is rare and the diagnosis can be difficult. The CRH test is of great assistance in the discrimination between ACTH-dependent and -independent CS. A cortisol increase of $>20 \%$ from the baseline has a high sensitivity for $\mathrm{CD}$. In our hands, the administration of CRH during IPSS has also been of great value in the investigation of paediatric CD. An IPS:P ratio $\geq 3.0$ indicates the presence of central ACTH secretion and an IPSG ratio of $\geq 1.4$ enables localisation of the side of the pituitary lesion. This clarification of the position of the pituitary microadenoma contributes to the success of TSS and the potential for a complete cure of $\mathrm{CD}$.

\section{References}

1 Michalkiewicz E, Sandrini R, Figueiredo B, Miranda EC, Caran E, Oliveira-Filho AG, Marques R, Pianovski MA, Lacerda L, Cristofani LM, Jenkins J, Rodriguez-Galindo C \& Ribeiro RC. Clinical and outcome characteristics of children with adrenocortical tumors: a report from the International Pediatric Adrenocortical Tumor Registry. Journal of Clinical Oncology 200422 838-845.

2 Storr H, Isidori A, Monson J, Besser G, Grossman A \& Savage M. Pre-pubertal Cushing's disease is more common in males, but there is no increase in severity at diagnosis. Journal of Clinical Endocrinology and Metabolism 200489 3818-3820.

3 Newell-Price J, Trainer P, Besser M \& Grossman A. The diagnosis and differential diagnosis of Cushing's syndrome and pseudoCushing's states. Endocrine Reviews 199819 647-672.

4 Arnaldi G, Angeli A, Atkinson AB, Bertagna X, Cavagnini F, Chrousos GP, Fava GA, Findling JW, Gaillard RC, Grossman AB, Kola B, Lacroix A, Mancini T, Mantero F, Newell-Price J, Nieman LK, Sonino N, Vance ML, Giustina A \& Boscaro M. Diagnosis and complications of Cushing's syndrome: a consensus statement. Journal of Clinical Endocrinology and Metabolism $2003 \mathbf{8 8}$ 5593-5602.

5 Ludecke DK, Flitsch J, Knappe UJ \& Saeger W. Cushing's disease: a surgical view. Journal of Neurooncology 2001 54 151-166.

6 Savage MO, Lienhardt A, Lebrethon MC, Johnston LB, Huebner A, Grossman AB, Afshar F, Plowman PN \& Besser GM. Cushing's disease in childhood: presentation, investigation, treatment and long-term outcome. Hormone Research 200155 24-30.

7 Vale W, Spiess J, Rivier C \& Rivier J. Characterization of a 41-residue ovine hypothalamic peptide that stimulates secretion of corticotropin and beta-endorphin. Science 1981213 1394-1397.

8 Shibahara S, Morimoto Y, Furutani Y, Notake M, Takahashi H, Shimizu S, Horikawa S \& Numa S. Isolation and sequence analysis of the human corticotropin-releasing factor precursor gene. EMBO Journal $19832775-779$.

9 Grossman AB, Howlett TA, Perry L, Coy DH, Savage MO, Lavender P, Rees LH \& Besser GM. CRF in the differential diagnosis of Cushing's syndrome: a comparison with the dexamethasone suppression test. Clinical Endocrinology (Oxf) 198829 167-178.

10 Kaye TB \& Crapo L. The Cushing syndrome: an update on diagnostic tests. Annals of Internal Medicine 1990 112 434-444.

11 Magiakou MA, Mastorakos G, Oldfield EH, Gomez MT, Doppman JL, Cutler GB, Jr, Nieman LK \& Chrousos GP. Cushing's syndrome in children and adolescents. Presentation, diagnosis and therapy. New England Journal of Medicine 1994331 629-636.

12 Oldfield EH, Doppman JL, Nieman LK, Chrousos GP, Miller DL, Katz DA, Cutler GB, Jr \& Loriaux DL. Petrosal sinus sampling with and without corticotropin-releasing hormone for the differential diagnosis of Cushing's syndrome. New England Journal of Medicine 1991325 897-905. 
13 Lienhardt A, Grossman AB, Dacie JE, Evanson J, Huebner A, Afshar F, Plowman PN, Besser GM \& Savage MO. Relative contributions of inferior petrosal sinus sampling and pituitary imaging in the investigation of children and adolescents with ACTH-dependent Cushing's syndrome. Journal of Clinical Endocrinology and Metabolism 200186 5711-5714.

14 Batista D, Gennari M, Riar J, Chang R, Keil MF, Oldfield EH \& Stratakis CA. An assessment of petrosal sinus sampling for localization of pituitary microadenomas in children with Cushing disease. Journal of Clinical Endocrinology and Metabolism $200691221-224$.
15 Storr HL, Afshar F, Matson M, Sabin I, Davies KM, Evanson J, Plowman PN, Besser GM, Monson JP, Grossman AB \& Savage MO. Factors influencing cure by transsphenoidal selective adenomectomy in paediatric Cushing's disease. European Journal of Endocrinology 2005152 825-833.

Received 24 April 2006

Accepted 22 June 2006 